\title{
Preparation of a Modified PTFE Fibrous Photo-Fenton Catalyst and Its Optimization towards the Degradation of Organic Dye
}

\author{
Zhizhong Ding, ${ }^{1}$ Yongchun Dong, ${ }^{1,2}$ and Bing Li ${ }^{1}$ \\ ${ }^{1}$ Division of Textile Chemistry \& Ecology, School of Textiles, Tianjin Polytechnic University, 399 Binshui Western Road, \\ Xiqing District, Tianjin 300387, China \\ ${ }^{2}$ State Key Laboratory Breeding Base of Photocatalysis, Fuzhou University, Fuzhou 350002, China
}

Correspondence should be addressed to Yongchun Dong, dyefib@yahoo.com.cn

Received 22 May 2012; Accepted 30 July 2012

Academic Editor: Meenakshisundaram Swaminathan

Copyright ( 2012 Zhizhong Ding et al. This is an open access article distributed under the Creative Commons Attribution License, which permits unrestricted use, distribution, and reproduction in any medium, provided the original work is properly cited.

\begin{abstract}
Polytetrafluoroethylene (PTFE) fiber was grafted with acrylic acid to impart the carboxyl groups onto the fiber surface, which were used to coordinate with both transition metal ions $\mathrm{Fe}(\mathrm{III})$ and $\mathrm{Cu}$ (II) and a rare metal ion $\mathrm{Ce}$ (III) to prepare the metal grafted PTFE fiber complexes as the novel heterogeneous Fenton catalysts for the degradation of the azo dye in water under visible irradiation. Some factors affecting the preparation process, such as nature and concentration of metal ions in the coordination solution, grafting degree of PTFE and reaction temperature were optimized with respect to the content and strength of metal fixation on the fiber and dye degradation efficiency. The results indicated that increasing metal ion concentrations in solution and grafting degree of PTFE fiber as well as higher coordination temperature led to a significant increase in metal content, especially $\mathrm{Fe}(\mathrm{III})$ and $\mathrm{Cu}(\mathrm{II})$ content of the complexes. $\mathrm{Fe}(\mathrm{III})$ ions fixed on the fiber showed the better catalytic performance than $\mathrm{Cu}(\mathrm{II})$ and $\mathrm{Ce}$ (III) ions fixed when three different complexes with similar metal content being employed, respectively. Moreover, Increasing Fe content or incorporation of $\mathrm{Cu}(\mathrm{II})$ ions could significantly improve the catalytic activity of the complexes.
\end{abstract}

\section{Introduction}

Dye-containing wastewater from different industrial fields is a principal source of environmental contamination. And these dyes are known to be largely nonbiodegradable and toxic to aquatic plants and animals. In recent years, heterogeneous Fenton process has become a research focus in the treatment of these dyes in water because of its application over a wide $\mathrm{pH}$ range and easy separation of the catalyst after the reaction. The modified polyacrylonitrile (PAN) fiber Fe complexes have been regarded as the attractive heterogeneous Fenton catalysts with low cost and high effectiveness [1-5]. However, it was reported that the modifications, especially amidoximation can lead to a significant decrease in the mechanical performance of PAN fiber. Moreover, the tensile strength of the amidoximated PAN fiber was found to be further lower after coordinating with $\mathrm{Fe}$ ions in our previous work $[2,6]$. This may limit its commercial applications in the future because good mechanical performance is necessary for effective using of the fibers as the catalysts for Fenton system.

Polytetrafluoroethylene (PTFE) fiber has received more and more attention in the past decades because of their outstanding thermal, chemical stability, and mechanical properties even under very harsh conditions [7-9]. In recent years, there have been many reports of using modified PTFE fibers and films containing functional groups for the concentration and separation of metal ions from aqueous media [10-12]. However, little attention has been paid to the heterogeneous Fenton catalyst produced by PTFE modification and metal coordination and its catalytic property for degradation of organic dye. Therefore, our investigations have been directed to the preparation of a fibrous PTFE catalyst with both good catalytic activity and mechanical strength. In this work, the influence of grafting degree of PTFE fiber, nature, and concentration of metal ion in the coordination solution and reaction temperature was optimized with respect to the content and strength of metal 


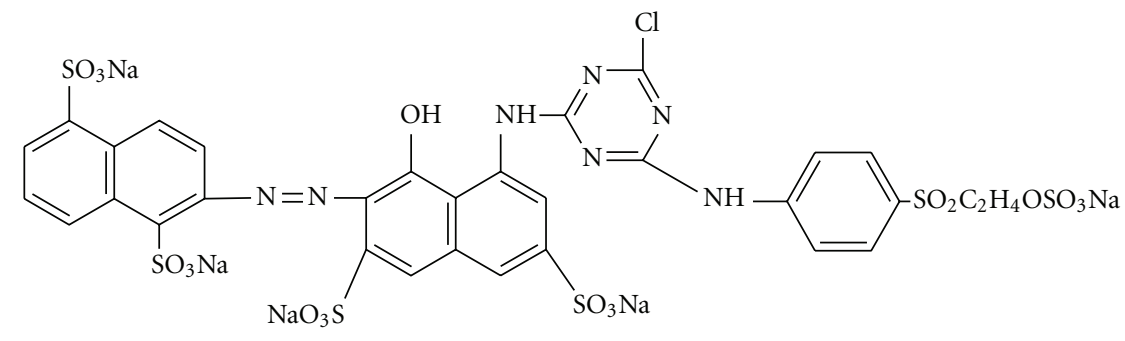

Scheme 1: Chemical structure of RR 195.

fixation on the fiber and decomposition efficiency of organic dye in aqueous solutions.

\section{Experimental}

2.1. Materials and Reagents. PTFE fibers were commercially available and provided by Fuxin Sengfuli Polymer Materials Co., China. Acrylic acid, hydrogen peroxide $(30 \%, w / w)$, and ammonium ferrous sulphate were of analytical grade. $\mathrm{FeCl}_{3} \cdot 7 \mathrm{H}_{2} \mathrm{O}, \mathrm{CuSO}_{4} \cdot 5 \mathrm{H}_{2} \mathrm{O}$ and $\mathrm{CeCl}_{3} \cdot 7 \mathrm{H}_{2} \mathrm{O}$ were used as the metal ions sources, respectively. Horseradish peroxidase (POD), N,N-diethyl-p-phenylene-deamine (DPD) and Reactive Red 195 (abbr. RR 195) was of laboratory agent grade and used without further purification. RR 195 was a typical azo dye and its molecular structure is presented in Scheme 1. Double distilled and deionized water was used throughout the study.

\subsection{Preparation of Metallic Modified PTFE Fiber Complexes}

2.2.1. Graft Polymerization of PTFE Fibers. Before modification, PTFE fibers were treated with acetone at room temperature for $30 \mathrm{~min}$, and then dried in a vacuum oven at $50^{\circ} \mathrm{C}$ for $48 \mathrm{~h} .10 .0 \mathrm{~g}$ of the dried fibers was immersed into the monomer solution containing $100 \mathrm{~mL}$ acrylic acid and $200 \mathrm{~mL}$ deionized water in a $500 \mathrm{~mL}$ flask. $3.0 \mathrm{wt} \%$ ammonium ferrous sulphate was also used in the monomer solution to minimize the homopolymerization of acrylic acid during the reaction. The flask containing the monomer solution and fibers was bubbled with nitrogen for $20 \mathrm{~min}$ to remove oxygen and sealed. The mixture in the flask was directly subjected to gammarays of irradiation from a ${ }^{60} \mathrm{Co}$ source at a dose rate of $0.5 \mathrm{kGyh}^{-1}$ for a given time. After irradiation, the grafted PTFE fibers (denoted as PAA-g-PTFE) were took out and washed with hot water, and acetone repeatedly to remove the residual monomer, homopolymers adhered to the fiber surface. Finally, the obtained grafted fibers were dried in a vacuum oven at $50^{\circ} \mathrm{C}$ for $24 \mathrm{~h}$ and weighed. The grafting degree was obtained using the following formula: $G_{f} \%=\left(W_{g} / W_{o}-1\right) \times 100 \%$, where $W_{o}$ and $W_{g}$ are the weights of the original and grafted fibers, respectively. It was noticed that the breaking strength of the original PTFE fiber was measured to be $93.35 \mathrm{CN}$, and little decrease in its breaking strength was observed after the polymerization.
2.2.2. Transition Metal PAA-g-PTFE Complexes. $5.0 \mathrm{~g}$ of PAA-g-PTFE was immersed in $150 \mathrm{~mL}$ of $\mathrm{FeCl}_{3}$ or $\mathrm{CuSO}_{4}$ aqueous solution, and then the mixture was treated at $50^{\circ} \mathrm{C}$ and $\mathrm{pH}$ 2.0-3.0 for a given time under continuous agitation. The resulting fibrous metal complexes were filtered, washed with deionized water and dried under vacuum at $60^{\circ} \mathrm{C}$ for $4.0 \mathrm{~h}$ to obtain $\mathrm{Fe}(\mathrm{III}-)$ grafted PTFE fiber complexes (denoted as Fe-PAA-g-PTFE) or Cu(II-) grafted PTFE fiber complexes (denoted as Cu-PAA-g-PTFE). The residual concentrations of $\mathrm{Fe}(\mathrm{III})$ or $\mathrm{Cu}(\mathrm{II})$ ions in the solutions after coordination were determined by using a WXF120 atomic absorption spectrometry (Beijing Rayleigh Analytical Instrument Corp., China) for calculating the Fe content $\left(Q_{\mathrm{Fe}-\mathrm{PTFE}}\right)$ or $\mathrm{Cu}$ content $\left(Q_{\mathrm{Cu}-\mathrm{PTFE}}\right)$ of the complexes.

2.2.3. Rare Metal PAA-g-PTFE Complexes. The complexes were prepared similarly to the transition metal PAA-g-PTFE complexes by using $\mathrm{CeCl}_{3}$ in the coordination solution. And the final complexes were denoted as Ce-PAA-g-PTFE. The Ce content ( $\left.Q_{\mathrm{Ce}-\mathrm{PTFE}}\right)$ of the complexes was measured and calculated by determining the residual $\mathrm{Ce}(\mathrm{III})$ ions in solution after coordination through a $\mathrm{Na}_{2}$-EDTA-based titrimetric method.

2.2.4. Cu-Fe Bimetallic PAA-g-PTFE Complexes. These complexes were also synthesized similarly to monometallic PAAg-PTFE complexes by using the mixed coordination solutions containing different concentration of $\mathrm{Fe}(\mathrm{III})$ and $\mathrm{Cu}(\mathrm{II})$ ions during the coordination processes. $\mathrm{Cu}-\mathrm{Fe}$ bimetallic PAA-g-PTFE complexes (denoted as Cu-Fe-PAA-g-PTFE) with different molar ratios of $\mathrm{Fe}$ (III) to $\mathrm{Cu}$ (II) ion (abbr. $\mathrm{Cu} / \mathrm{Fe}$ molar ratio) were produced by adjusting the concentrations of the metal ions in coordination solution, and in which the concentrations of total metal ions were kept constant at $0.10 \mathrm{~mol} \mathrm{~L}^{-1}$.

2.3. Catalytic Activity of the Complex towards $\mathrm{H}_{2} \mathrm{O}_{2}$ Decomposition. The decomposition of $\mathrm{H}_{2} \mathrm{O}_{2}$ was carried out at the $150 \mathrm{~mL}$ Pyrex vessels inside the photoreaction reaction system. A $400 \mathrm{~W}$ high pressure mercury lamp (Foshan Osram Illumination Co., China) was used as the illuminating source for photocatalytic reaction. A cutoff filter was used to ensure irradiation only by visible light $(\lambda>420 \mathrm{~nm})$ for the high pressure mercury lamp. The intensity of visible light irradiation over the surface of test solution inside photoreaction system was measured to be $9.65 \mathrm{Wcm}^{-2}$ using 


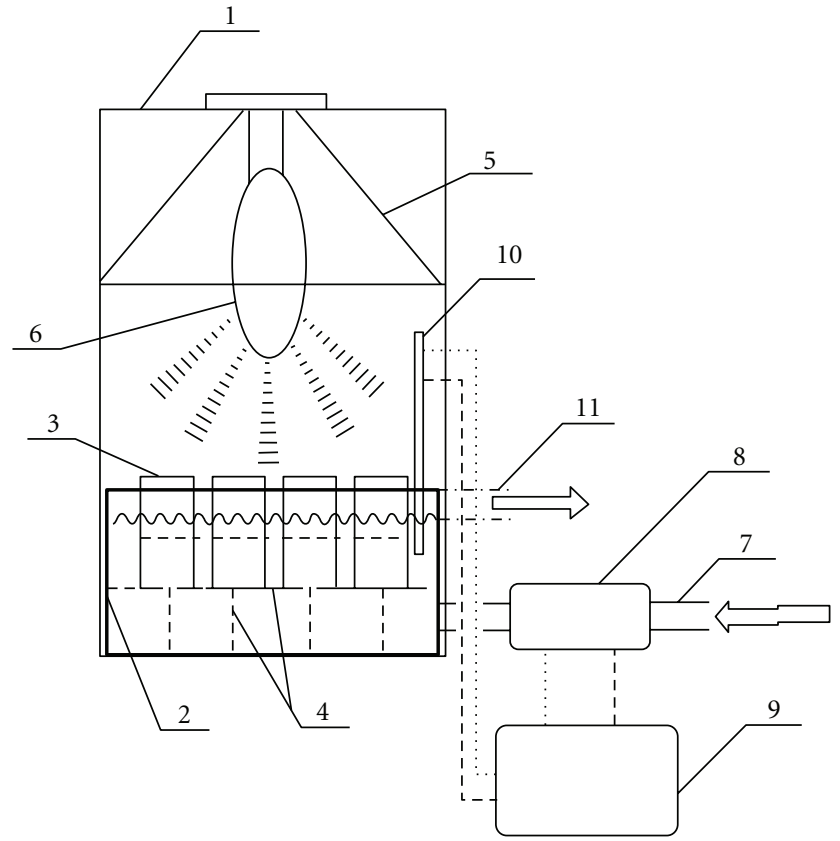

(1) Chamber

(2) Water bath

(3) Glass vessel

(4) Support

(5) Lamp-chimney

(6) Mercury lamp

FIgURE 1: The schematic diagram of photoreaction system.

FZ-A radiometer (BNU Light and Electronic Instrumental Co., China), respectively. The diagram of the photoreaction system was presented in Figure 1.

$1.0 \mathrm{~g}$ of the complex was placed into the vessels containing $100 \mathrm{~mL} \mathrm{H}_{2} \mathrm{O}_{2}$ solution of concentration $10.0 \mathrm{mmol} \mathrm{L}^{-1}$ at $25^{\circ} \mathrm{C}$. The residual concentration of $\mathrm{H}_{2} \mathrm{O}_{2}$ in the solution during the reaction was determined though the spectrophotometric DPD method, in which the DPD was oxidized by $\mathrm{H}_{2} \mathrm{O}_{2}$ based on the POD catalyzed reaction [13]. The analysis of the residual concentration of $\mathrm{H}_{2} \mathrm{O}_{2}$ was repeated three times for each sample and the results averaged.

2.4. Dye Degradation Procedure. The dye degradation was performed in the photoreaction reaction system mentioned above under visible irradiation. $0.40 \mathrm{~g}$ of metal PAA-g-PTFE complex was added into $100 \mathrm{~mL}$ of test solution containing $0.04 \mathrm{mmol} \mathrm{L}^{-1} \mathrm{RR} 195$ and $6.0 \mathrm{mmol} \mathrm{L}^{-1} \mathrm{H}_{2} \mathrm{O}_{2}$. The reaction temperature was kept at $25 \pm 1^{\circ} \mathrm{C}$, and the $\mathrm{pH}$ of the solution was adjusted with $0.10 \mathrm{mmol} \mathrm{L}^{-1} \mathrm{HNO}_{3}$ and/or $\mathrm{NaOH}$ aqueous solution and measured using DHS-25C digital pH meter (Shanghai Jingmi Instrumental Co., China). The degradation of the dye was initialized after the adsorption/desorption equilibrium of the dye on the complex was reached in the dark for $2.0 \mathrm{~h}$. At given irradiation time intervals, $1-2 \mathrm{~mL}$ of the test solution was sampled from the reaction vessel and analyzed immediately by recording the UV-vis spectrum

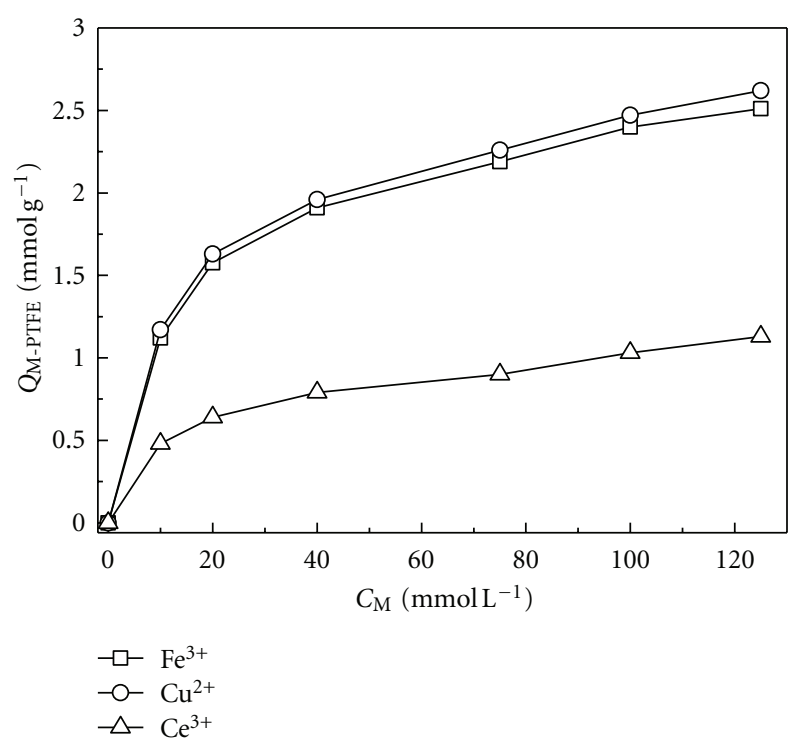

Figure 2: Effect of $C_{\mathrm{M}}$ on $Q_{\mathrm{M} \text {-PTFE }}$ of the complexes during the preparation.

of the dye at the $\lambda_{\max }(523 \mathrm{~nm})$ with a UV-2401 Shimadzu spectrophotometer. The decoloration percentage of the dye was expressed as $D \%=\left(1-C_{d} / C_{d, 0}\right) \times 100 \%$, where $C_{d, 0}$ and $C_{d}$ are the initial and residual concentrations of the dye $\left(\mathrm{mmol} \mathrm{L}^{-1}\right)$, respectively. Moreover, total organic carbon (TOC) was assayed in the dye degradation process by using a Phoenix 8000 TOC analyzer (Tekmar-Dehrmann Inc., USA) and TOC removal percentage of the dye was calculated as follows: TOC removal $\%=\left(1-\mathrm{TOC}_{t} / \mathrm{TOC}_{0}\right) \times 100 \%$, where $\mathrm{TOC}_{0}$ and $\mathrm{TOC}_{t}$ are the TOC values $\left(\mathrm{mg} \mathrm{L}^{-1}\right)$ at reaction times 0 and $t$, respectively.

2.5. Metal Ions Leaching from the Complex. $0.40 \mathrm{~g}$ of metal PTFE fiber complex was placed into in $100 \mathrm{~mL}$ solution containing $6.0 \mathrm{mmol} \mathrm{L}^{-1} \quad \mathrm{H}_{2} \mathrm{O}_{2}$. The leaching of $\mathrm{Fe}(\mathrm{III})$ or/and $\mathrm{Cu}(\mathrm{II})$ ions from the complex in solution at room temperature and under visible light irradiation was carried out for $300 \mathrm{~min}$. And the concentrations of $\mathrm{Fe}(\mathrm{III})$ or $\mathrm{Cu}$ (II) ions in solution at intervals of time were measured using atomic absorption spectrometry method, respectively.

\section{Results and Discussion}

\subsection{Optimization of Coordination Parameters with respect to Metal Contents on PAA-g-PTFE}

3.1.1. Metal Ion Concentration in Coordination Solution. In order to investigate the effect of metal ion concentration in coordination solution $\left(C_{\mathrm{M}}\right)$ on metal content on PAA-gPTFE ( $\left.Q_{\text {M-PTFE}}\right)$, three metal ions including $\mathrm{Fe}(\mathrm{III}), \mathrm{Cu}(\mathrm{II})$, and $\mathrm{Ce}(\mathrm{III})$ ions were selected to react with PAA-g-PTFE with $G_{f} \%$ of 34.53 at $50^{\circ} \mathrm{C}$, and results were shown in Figure 2.

It is seen from Figure 2 that all the $Q_{\mathrm{M}-\mathrm{PTFE}}$ values significantly increase with increasing $C_{\mathrm{M}}$, and the increasing tendency gradually declines when $C_{M}$ being above 


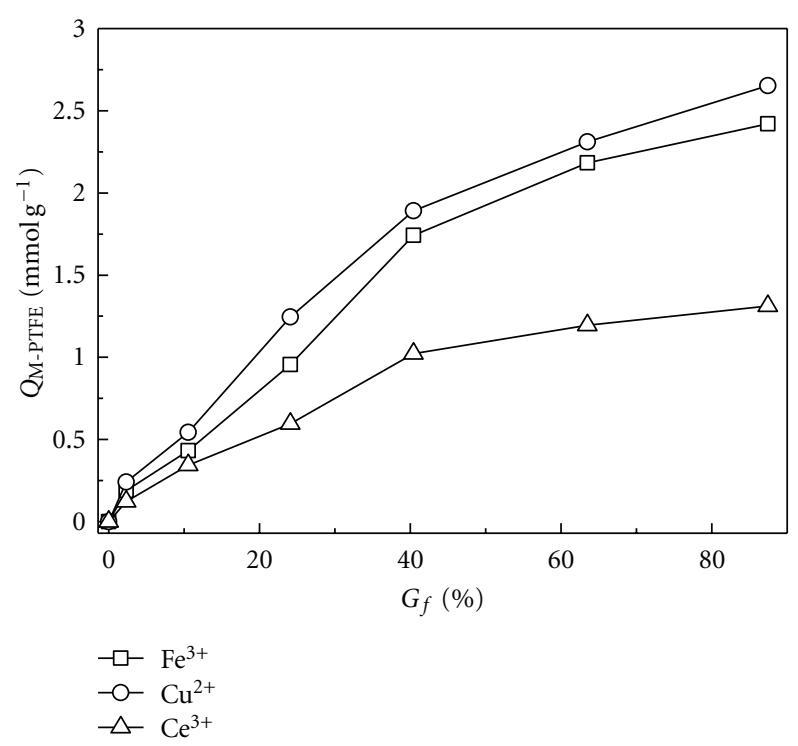

Figure 3: QM-PTFE of the complexes as a function of graft degree of PAA-g-PTFE.

$40.0 \mathrm{mmol} \mathrm{L}^{-1}$, especially for $\mathrm{Ce}(\mathrm{III})$ ions. This suggests that higher $C_{M}$ can enhance the coordination of PAA-g-PTFE with metal ions, particularly two transition metal ions. The previous works $[11,12,14]$ have found that the carboxyl groups on PAA-g-PTFE are the main coordinating sites with metal ions. Furthermore, it has been proposed that the oxygen of the carboxyl group has a pair of electrons that can add themselves to a proton or a metal ion to form a complex through a coordinated covalent bond. The metal ions with empty orbitals act as a Lewis acid capable of accepting electron pairs. In contrast, the carboxyl groups that have nonshared electron pairs function as Lewis bases donating their electrons pair $[15,16]$. Moreover, transition metal contents $\left(Q_{\mathrm{Fe}-\mathrm{PTFE}}\right.$ and $\left.Q_{\mathrm{Cu}-\mathrm{PTFE}}\right)$ on the fiber are much more than Ce content ( $Q_{\text {Ce-PTFE }}$ ) on the fiber, especially at higher metal concentration in solution. This is because the $4 \mathrm{f}$ electrons of rare earth metal ion are in the inner orbital of the atomic structure, so that the ligand field has less effect on them and the rare earth metal ions have much lower LFSE values $\left(4.18 \mathrm{~kJ} \mathrm{moL}^{-1}\right)$ than d-transition metal ions $(\geq$ $\left.418 \mathrm{~kJ} \mathrm{moL}^{-1}\right)[5,17]$.

3.1.2. Graft Degree of PAA-g-PTFE. To determine the dependence of $Q_{M}$-PTFE value on graft degree of PAA-g-PTFE, the complexes were produced by the coordination of PAA-gPTFE with different $G_{f} \%$ in $0.10 \mathrm{~mol} \mathrm{~L}^{-1}$ metal ion aqueous solution at $50^{\circ} \mathrm{C}$, and relationship between $G_{f} \%$ and $Q_{\mathrm{M}-\mathrm{PTFE}}$ values was presented in Figure 3.

Figure 3 shows that the $Q_{\mathrm{M}-\mathrm{PTFE}}$ value of metal PAA-gPTFE complexes was greatly enhanced with $G_{f} \%$ of PAAg-PTFE, particularly when $\mathrm{Fe}(\mathrm{III})$ and $\mathrm{Cu}(\mathrm{II})$ ion being used. This indicates that increasing $G_{f} \%$ value can benefit the fixation of three metal ions on the surface of PAA-gPTFE and form the metal PAA-g-PTFE complexes with high $Q_{\text {M-PTFE }}$ because PAA-g-PTFE with high $G_{f} \%$ values has

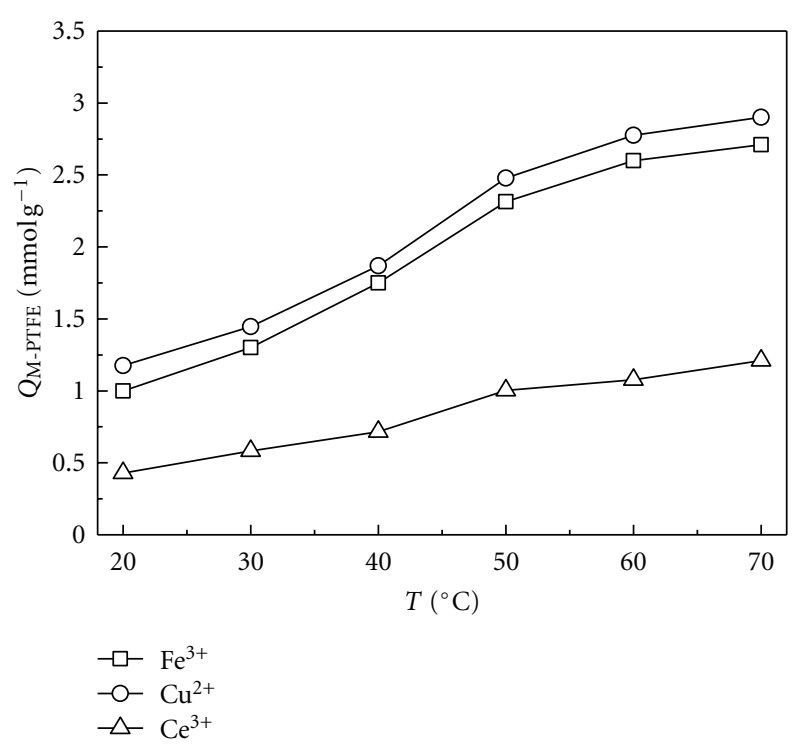

Figure 4: QM-PTFE of the complexes at different reaction temperatures.

much more carboxyl groups on their surface than those with low $G_{f} \%$ values, thus more easily react with metal ions in solution.

3.1.3. Temperature. PAA-g-PTFE with $G_{f} \%$ of 34.53 was employed to coordinate with three metal ions, respectively, in the solution, for investigating the impact of reaction

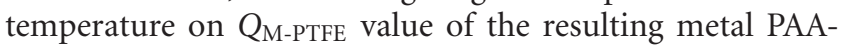
g-PTFE complexes, and results were shown in Figure 4.

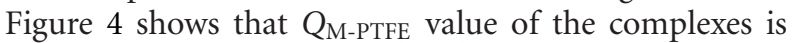
increased with elevation of reaction temperature from 20 to $70^{\circ} \mathrm{C}$. This obviously demonstrates that it is favorable for the coordination with the temperature rising, which implies that the coordination process is an endothermic process [11]. A possible reason is that higher temperature increases mobility of the polymer chains and the swelling of the fiber in the reaction medium, thus improving the interactions between metal ion and the fiber and resulting in more metal ions fixed on them.

3.2. Comparison of Metal Ions toward $\mathrm{H}_{2} \mathrm{O}_{2}$ Decomposition. The catalytic activity of three metal PAA-g-PTFE complexes with similar QM-PTFE value (approximately $1.30 \mathrm{mmol} \mathrm{L}^{-1}$ ) was examined with respect to the decomposition of $\mathrm{H}_{2} \mathrm{O}_{2}$, respectively, and the decay ratios of $\mathrm{H}_{2} \mathrm{O}_{2}$ as the function of irradiation time were shown in Figure 5.

It is observed from Figure 5 that the decay ratios of $\mathrm{H}_{2} \mathrm{O}_{2}$ gradually decline with the increasing irradiation time and vary with the nature of metal ions. The decay ratio of $\mathrm{H}_{2} \mathrm{O}_{2}$ is the lowest for Fe-PAA-g-PTFE, followed by Cu-PAA-gPTFE, and the highest for Ce-PAA-g-PTFE. This indicates that Fe-PAA-g-PTFE has a stronger catalytic activity than the other complexes at the same conditions. Additionally, from the viewpoint of the toxicity and cost of three metal ions, 


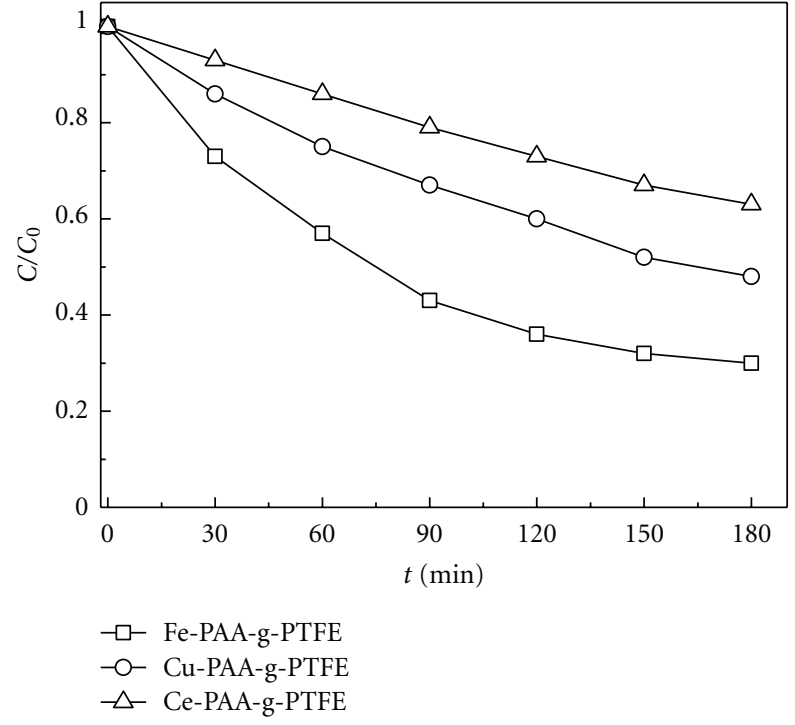

FIgURE 5: Decomposition of $\mathrm{H}_{2} \mathrm{O}_{2}$ in the presence of the different catalysts.

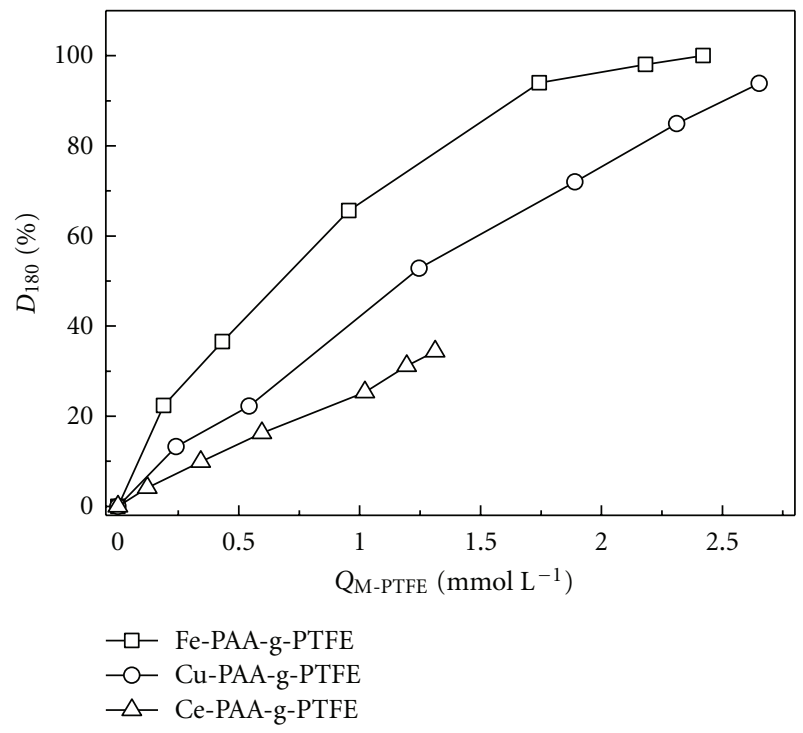

Figure 6: Relationship between $Q_{\mathrm{M}-\mathrm{PTFE}}$ and $D_{180} \%$.

$\mathrm{Fe}$ (III) ions should been selected to prepare the catalyst for the majority of the future research and practical application.

3.3. Effect of Metal Ion on Dye Degradation. The dye degradations were conducted in the presence of three metal PAA-g-PTFE complexes with different $Q_{\mathrm{M}-\mathrm{PTFE}}$ values as the heterogeneous Fenton catalysts, respectively, and the

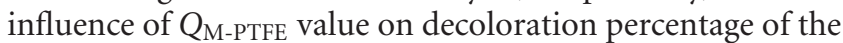
dye within $180 \min \left(D_{180} \%\right)$ was presented in Figure 6.

Figure 6 shows that increasing $Q_{\mathrm{M}-\mathrm{PTFE}}$ value can remarkably enhance the dye degradation for all the complexes, particularly Fe-PAA-g-PTFE. Moreover, comparing three metal PAA-g-PTFE complexes with similar $Q_{\mathrm{M}-\mathrm{PTFE}}$ values, the highest $D_{180} \%$ is achieved when Fe-PAA-g-PTF is used.
This means that Fe-PAA-g-PTFE exhibits the strongest catalytic activity for dye degradation, of three complexes. The main reason is that Fe-PAA-g-PTFE leads to the enhanced decomposition of $\mathrm{H}_{2} \mathrm{O}_{2}$ in solution indicated in Figure 5, thus possibly producing more hydroxyl radicals, which is responsible for the dye degradation. This reaction process is described by (1) and (2). On the other hand, the formed $\mathrm{Fe}$ (II) ions on Fe-PAA-g-PTFE may be oxidized to $\mathrm{Fe}(\mathrm{IV})$ ions in this work, which are regarded as another reactive intermediate from the photo-Fenton reaction which can decompose dye molecules. A possible formation of $\mathrm{Fe}(\mathrm{IV})$ ions was expressed by (3)

$$
\begin{gathered}
\mathrm{Fe}^{3+} / \mathrm{PTFE}+\mathrm{H}_{2} \mathrm{O}_{2} \stackrel{h v}{\longrightarrow} \mathrm{Fe}^{2+} / \mathrm{PTFE}+\mathrm{HO}_{2} \cdot \mathrm{H}^{\oplus} \\
\mathrm{Fe}^{2+} / \mathrm{PTFE}+\mathrm{H}_{2} \mathrm{O}_{2} \stackrel{h v}{\longrightarrow} \mathrm{Fe}^{3+} / \mathrm{PTFE}+\mathrm{OH}^{\ominus}+\mathrm{HO}^{\bullet} \\
\mathrm{Fe}^{2+} / \mathrm{PTFE}+\mathrm{H}_{2} \mathrm{O}_{2} \stackrel{h v}{\longrightarrow} \mathrm{Fe}^{4+} / \mathrm{PTFE} \stackrel{h v}{\longrightarrow} \mathrm{Fe}^{3+} / \mathrm{PTFE} \\
\mathrm{Dye}+\mathrm{Fe}^{3+} / \mathrm{PTFE} \stackrel{h v}{\longrightarrow} \mathrm{Dye}^{*} \cdots \mathrm{Fe}^{3+} / \mathrm{PTFE} \longrightarrow \mathrm{Dye}^{+\bullet} \\
+\mathrm{Fe}^{2+} / \mathrm{PTFE} .
\end{gathered}
$$

Additionally, the photosensitization of the azo dyes can promote a conversion of $\mathrm{Fe}$ (III) to $\mathrm{Fe}(\mathrm{II})$ ions during photoassisted Fenton reaction [12]. In this work, it is believed that RR 195 could act as the sensitizer of Fe-PAA-g-PTFE to lead to a charge transfer with the concomitant quenching of the excited dye* and the formation of $\mathrm{dye}^{+}$. This process was suggested by (4).

It is well known the hydroxyl radicals is a powerful oxidant and can ultimately cause mineralization of textile dyes. Consequently, the mineralization of the dye was examined by measuring the TOC values of test solutions during the degradation when three complexes with the similar $Q_{\text {M-PTFE }}$ values were employed, respectively.

Figure 7 shows that TOC removal \% of the dye is as a function of irradiation time. It is found that TOC removal $\%$ gradually increases with the prolongation of irradiation time. Specifically, TOC removal \% for Fe-PAA-g-PTF is much higher than those for the other complexes at the same time. These results demonstrate that three metal PAAg-PTFE complexes as the photocatalysts can result in a drastic breakdown of dye molecules, and then convert them into water, carbon dioxide, and inorganic compounds. It should also be pointed out that TOC removal \% is mainly determined by nature of metal ions, which is well consistent with the impact of nature of metal ions on the degradation mentioned above.

In order to study the catalytic activity of the complexes in a wide $\mathrm{pH}$ range, the dye degradation was carried out at different solution $\mathrm{pH}$ within $180 \mathrm{~min}$ of reaction time. The catalytic activity of the complexes was determined with respect to the dye degradation with the results presented in Figure 8.

Figure 8 shows that the dye degradation can be operated in the presence of the complex over a wide $\mathrm{pH} 3-9$ range, indicating that a significant breakdown of the dye occur, especially at acidic media. Moreover, the catalytic activity 


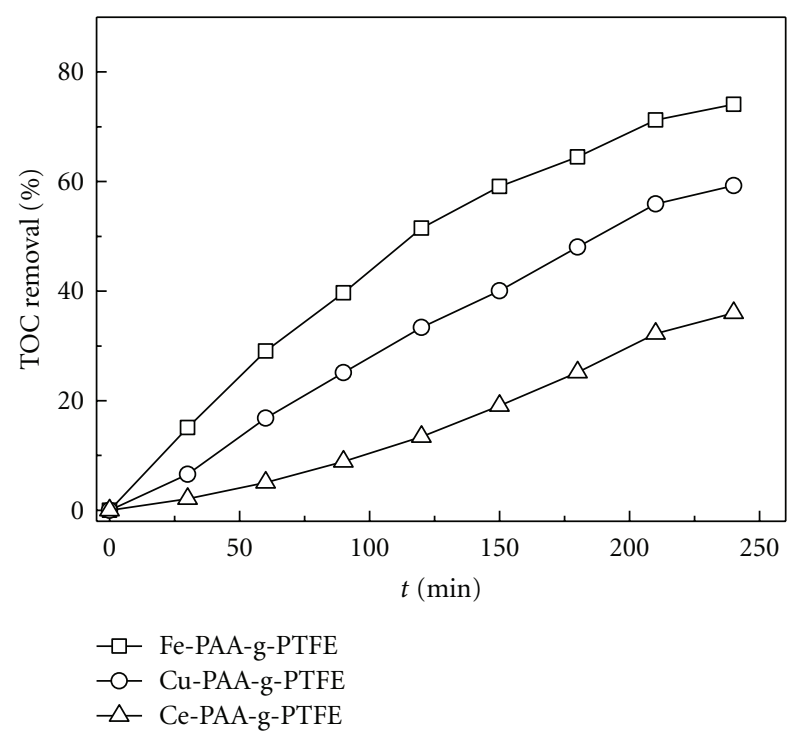

Figure 7: Mineralization of the dye with different catalysts.

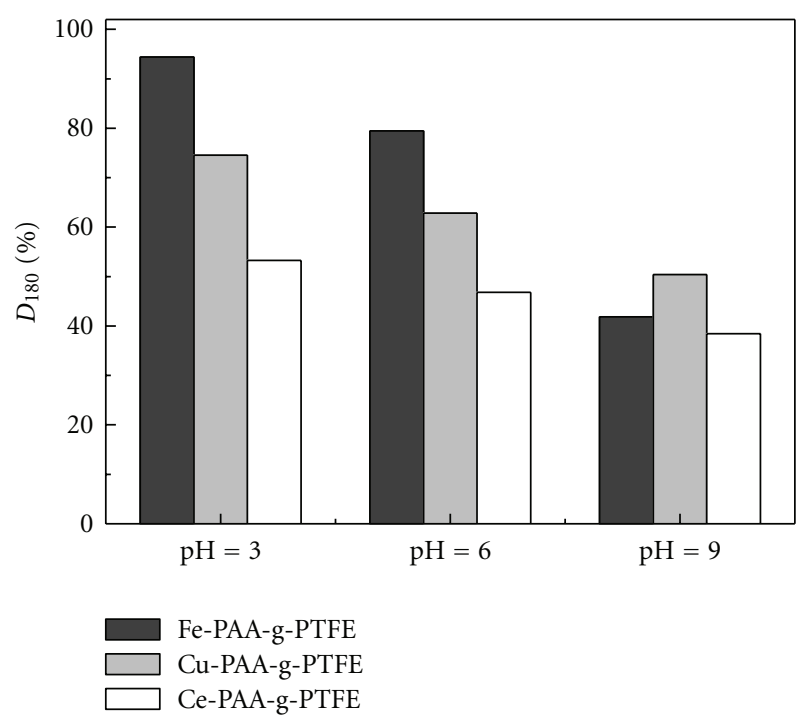

Figure 8: Dye degradation at different $\mathrm{pH}$ levels for three catalysts.

of three complexes at acid and neutral medium is ranked in this order: Fe-PAA-g-PTFE $>$ Cu-PAA-g-PTFE $>$ CePAA-g-PTFE. However, higher $\mathrm{pH}$ range, especially alkaline $\mathrm{pH}$ medium dramatically decreases the catalytic activity of three complexes. It is worth noticing that Cu-PAA-gPTFE shows a stronger activity than Fe-PAA-g-PTFE at pH 9. This is similar to the performance of $\mathrm{Cu} / \mathrm{MCM}-41$ as a highly stable and $\mathrm{pH}$-insensitive heterogeneous photoFenton-like Fenton catalyst [18]. Some researches [18, 19] suggested that an advantage of $\mathrm{Cu}^{2+}$ ion as a Fenton-like catalyst is its characteristics of a wide-working $\mathrm{pH}$ range compared to the conventional Fenton catalyst. Therefore it is believed that $\mathrm{Cu}$-PAA-g-PTFE behaves similarly to Fe-PAA$\mathrm{g}$-PTFE, and it has a higher catalytic activity over a wide $\mathrm{pH}$ range.
3.4. Role of $\mathrm{Cu}$ (II) Ion as an Assisted Metal Ion. It has been suggested that the performance of supported Fe catalysts is often improved by adding certain metals. And copper ion has a role as an assistant in photocatalysis [5]. Moreover, it has been presented that the outstanding catalytic activity of bimetal catalysts may be generally ascribed to synergistic effects between copper and iron redox couples. In order to meet the demands for rapid and stable dye degradation in future commercial application, a series of $\mathrm{Cu}-\mathrm{Fe}$ bimetal PAA-g-PTFE complexes with different $\mathrm{Cu} / \mathrm{Fe}$ molar ratios were prepared and used in the dye degradation at $\mathrm{pH} 9$ in this work. And $\mathrm{Cu} / \mathrm{Fe}$ molar ratio of metal PAA-g-PTFE complexes was observed to have a significant impact on the decomposition efficiency of the dye, and the results are given in Table 1.

The data in Table 1 indicate that higher concentration of $\mathrm{Cu}(\mathrm{II})$ ions in the solutions increased their $\mathrm{Cu} / \mathrm{Fe}$ molar ratio. When the molar concentration of $\mathrm{Cu}$ (II) ions equals to that of $\mathrm{Fe}(\mathrm{III})$ ions in the solution, the $\mathrm{Cu} / \mathrm{Fe}$ molar ratio of $\mathrm{Cu}-\mathrm{Fe}-\mathrm{PAA}-\mathrm{g}-\mathrm{PTF}$ is 2.87 , much more than 1.0, suggesting that PAA-g-PTF has much higher affinity for $\mathrm{Cu}$ (II) ions than $\mathrm{Fe}$ (III) ions at the same conditions. More importantly, $D_{180} \%$ and TOC removal $\%$ of dye degradation in the presence of the bimetal PAA-g-PTFE complexes is much higher than those in the presence of the monometal PAA-g-PTE complexes, and the maximum $D_{180} \%$ and TOC removal \% was achieved for Cu-Fe-PAA-g-PTFE (ii). These results confirm that catalytic activity of metal PAA-g-PTFE complexes depends highly upon their $\mathrm{Cu} / \mathrm{Fe}$ molar ratio, and $\mathrm{Cu}-\mathrm{Fe}-\mathrm{PAA}-\mathrm{g}-\mathrm{PTFE}$ (ii) with a $\mathrm{Cu} / \mathrm{Fe}$ molar ratio of 2.87 shows the best catalytic activity at alkaline $\mathrm{pH}$ medium. This demonstrates the existence of synergetic effect between loaded $\mathrm{Fe}(\mathrm{III})$ and $\mathrm{Cu}(\mathrm{II})$ ions in the bimetal PAA-g-PTFE complexes, which improved their catalytic activity to a great extent. The main reason may be that the $\mathrm{H}_{2} \mathrm{O}_{2}$ molecules absorbed on the surface of $\mathrm{Cu}-\mathrm{Fe}-\mathrm{PAA}-\mathrm{g}-\mathrm{PTFE}$ can reduce $\mathrm{Fe}(\mathrm{III})$ to $\mathrm{Fe}(\mathrm{II})$ ions through the Fenton-like process under visible light irradiation, and the generated $\mathrm{Fe}$ (II) ions are then oxidized by $\mathrm{H}_{2} \mathrm{O}_{2}$ to complete the $\mathrm{Fe}(\mathrm{III}) / \mathrm{Fe}(\mathrm{II})$ ions cycle and produce hydroxyl radicals. Meanwhile, the formed $\mathrm{Fe}(\mathrm{II})$ ions can also react with the loaded $\mathrm{Cu}$ (II) ions to form the $\mathrm{Cu}(\mathrm{I})$ and $\mathrm{Fe}(\mathrm{III})$ ions (5) to accelerate the transformation of $\mathrm{Fe}(\mathrm{III}) / \mathrm{Fe}(\mathrm{II})$ ions and $\mathrm{Cu}(\mathrm{II}) / \mathrm{Cu}(\mathrm{I})$ ions in $\mathrm{Cu}-\mathrm{Fe}-\mathrm{PAA}-\mathrm{g}$-PTFE, thus giving rise to additional hydroxyl radicals during the degradation:

$$
\mathrm{Fe}^{3+} / \mathrm{PTFE}+\mathrm{Cu}^{+} / \mathrm{PTFE} \rightleftharpoons \mathrm{Fe}^{2+} / \mathrm{PTFE}+\mathrm{Cu}^{2+} / \mathrm{PTFE} .
$$

3.5. Metal Ions Leaching from the Catalyst. One problem with the heterogeneous photocatalysts is metal leaching from the catalyst that causes secondary contamination to wastewater in pilot-scale application. The leaching concentrations of metal ions from metal PAA-g-PTFE complexes in solution were measured. The results indicated that metal ions were continuously leached out from the complexes after the reaction started, and the final measured concentrations of both metal ions in the solution within $300 \mathrm{~min}$ at different pH levels were shown in Tables 2 and 3. 
TABLE 1: Effect of $\mathrm{Cu} / \mathrm{Fe}$ molar ratio of the catalysts on dye decomposition.

\begin{tabular}{|c|c|c|c|c|c|c|c|c|}
\hline \multirow{2}{*}{ Samples } & \multicolumn{2}{|c|}{$C_{\mathrm{M}}\left(\mathrm{mol} \mathrm{L}^{-1}\right)$} & \multicolumn{3}{|c|}{$Q_{\text {M-PTFE }}\left(\mathrm{mmol} \mathrm{L}^{-1}\right)$} & \multirow{2}{*}{$\mathrm{Cu} / \mathrm{Fe}$} & \multirow{2}{*}{$D_{180} \%$} & \multirow{2}{*}{ TOC Removal \% } \\
\hline & $\mathrm{Fe}(\mathrm{III})$ & $\mathrm{Cu}(\mathrm{II})$ & $\mathrm{Fe}(\mathrm{III})$ & $\mathrm{Cu}(\mathrm{II})$ & Total & & & \\
\hline Fe-PAA-g-PTFE & 0.100 & 0.000 & 1.89 & 0.00 & 1.89 & 0 & 47.3 & 37.3 \\
\hline Cu-Fe-PAA-g-PTFE (i) & 0.075 & 0.025 & 1.13 & 0.75 & 1.88 & 0.66 & 61.2 & 54.6 \\
\hline Cu-Fe-PAA-g-PTFE (ii) & 0.050 & 0.050 & 0.54 & 1.55 & 2.09 & 2.87 & 84.6 & 72.7 \\
\hline Cu-Fe-PAA-g-PTFE (iii) & 0.025 & 0.075 & 0.31 & 1.75 & 2.06 & 5.65 & 78.4 & 56.7 \\
\hline Cu-PAA-g-PTFE & 0.000 & 0.100 & 0.00 & 1.98 & 1.98 & l & 51.9 & 45.1 \\
\hline
\end{tabular}

TABLE 2: Leaching of Fe ions from Fe-PAA-g-PTFE with different $Q_{\mathrm{Fe}}$ values.

\begin{tabular}{lccc}
\hline Fe-PAA-g-PTFE & \multicolumn{2}{c}{$\begin{array}{c}\text { Fe(III) ions concentration in solution } \\
\left(\mathrm{mg} \mathrm{L}^{-1}\right)\end{array}$} \\
& $\mathrm{pH}=3$ & $\mathrm{pH}=7$ & $\mathrm{pH}=9$ \\
\hline$Q_{\mathrm{Fe}}=0.432 \mathrm{mmol} \mathrm{L}^{-1}$ & 0.49 & 0.37 & 0.07 \\
$\mathrm{QFe}_{\mathrm{Fe}}=0.955 \mathrm{mmol} \mathrm{L}^{-1}$ & 0.72 & 0.57 & 0.15 \\
$\mathrm{QFe}_{\mathrm{Fe}}=1.743 \mathrm{mmol} \mathrm{L}^{-1}$ & 0.95 & 0.73 & 0.22 \\
$\mathrm{Q}_{\mathrm{Fe}}=2.183 \mathrm{mmol} \mathrm{L}^{-1}$ & 1.22 & 0.94 & 0.43 \\
$Q_{\mathrm{Fe}}=2.421 \mathrm{mmol} \mathrm{L}^{-1}$ & 1.53 & 1.23 & 0.57 \\
\hline
\end{tabular}

TABLE 3: Impact of $\mathrm{Cu} / \mathrm{Fe}$ molar ratio on leaching of metal ions from $\mathrm{Cu}-\mathrm{Fe}$ bimetallic PTFE fiber complexes.

\begin{tabular}{|c|c|c|c|c|c|c|}
\hline \multirow{3}{*}{ Samples } & \multicolumn{6}{|c|}{ Metal ions concentration in solution $\left(\mathrm{mg} \mathrm{L}^{-1}\right)$} \\
\hline & \multicolumn{2}{|c|}{$\mathrm{pH}=3$} & \multicolumn{2}{|c|}{$\mathrm{pH}=7$} & \multicolumn{2}{|c|}{$\mathrm{pH}=9$} \\
\hline & $\mathrm{Fe}(\mathrm{III})$ & $\mathrm{Cu}(\mathrm{II})$ & $\mathrm{Fe}(\mathrm{III})$ & $\mathrm{Cu}(\mathrm{II})$ & $\mathrm{Fe}(\mathrm{III})$ & $\mathrm{Cu}(\mathrm{II})$ \\
\hline Fe-PAA-g-PTFE & 0.93 & 0.00 & 0.82 & 0.00 & 0.29 & 0.00 \\
\hline $\begin{array}{l}\text { Cu-Fe-PAA-g-PTFE } \\
\text { (i) }\end{array}$ & 0.63 & 0.35 & 0.53 & 0.29 & 0.19 & 0.12 \\
\hline $\begin{array}{l}\text { Cu-Fe-PAA-g-PTFE } \\
\text { (ii) }\end{array}$ & 0.21 & 0.76 & 0.13 & 0.49 & 0.06 & 0.24 \\
\hline $\begin{array}{l}\mathrm{Cu}-\mathrm{Fe}-\mathrm{PAA}-\mathrm{g}-\mathrm{PTFE} \\
\text { (iii) }\end{array}$ & 0.17 & 0.92 & 0.10 & 0.45 & 0.08 & 0.19 \\
\hline Cu-PAA-g-PTFE & 0.00 & 1.25 & 0.00 & 0.89 & 0.00 & 0.31 \\
\hline
\end{tabular}

It can be noticed from Table 2 that increasing $Q_{\mathrm{Fe}}$ value is accompanied by increasing Fe ion concentration in solution at three investigated $\mathrm{pH}$ levels. This means that Fe-PAA-g-PTFE with higher $Q_{F e}$ value can leach more $\mathrm{Fe}(\mathrm{III})$ ions than that with lower $Q_{\mathrm{Fe}}$ value. It is obvious from the results shown in Table 3 that $\mathrm{Fe}(\mathrm{III})$ and $\mathrm{Cu}(\mathrm{II})$ ion concentrations in solution are much affected by $\mathrm{Cu} / \mathrm{Fe}$ molar ratio of the complexes. On the other hand, higher $\mathrm{pH}$ level caused a gradual decrease in leached Fe(III) or $\mathrm{Cu}$ (II) ion concentration in solution, revealing that metal ions leaching from the complexes is dependent on the solution $\mathrm{pH}$. Moreover, it should be pointed out that the final leached concentration of $\mathrm{Fe}(\mathrm{III})$ or $\mathrm{Cu}(\mathrm{II})$ ions is lower than $1.0 \mathrm{mg} \mathrm{L}^{-1}$ for both complexes, especially at $\mathrm{pH} 7$ and 9 . This result implies that both metal ions were attached on the surface of the modified PTFE via the hydroxyl group. Thus, these complexes can be regarded as the effective and stable heterogeneous photocatalysts for the dye degradation over a broad $\mathrm{pH}$ range due to a minimal threshold concentration of 3-15 mg L $\mathrm{L}^{-1} \mathrm{Fe}$ which allows the homogeneous Fenton reaction to proceed within a reasonable period of time. Additionally, it is well known that $\mathrm{Cu}$ ion is hazardous to both marine animals and humans. The discharge standard was suggested by the Environmental Protection Agency is $1.0 \mathrm{mg} \mathrm{L}^{-1}$ [18], which is higher than the final leached concentration of $\mathrm{Cu}(\mathrm{II})$ ions for $\mathrm{Cu}-\mathrm{Fe}$ bimetallic PTFE fiber complexes except $\mathrm{Cu}-\mathrm{Fe}-\mathrm{PAA}-\mathrm{g}-\mathrm{PTFE}$ (iii) and $\mathrm{Cu}-\mathrm{PAA}-\mathrm{g}-$ PTFE.

\section{Conclusions}

The novel heterogeneous photo-Fenton catalysts were produced by a modification of PTFE fibers through graft polymerization of acrylic acid to introduce the carboxyl groups onto the fiber surface, which were used to coordinate with transition metal ions $(\mathrm{Fe}(\mathrm{III})$ and $\mathrm{Cu}(\mathrm{II}))$ or rare metal ion $(\mathrm{Ce}(\mathrm{III}))$. Increasing metal ion concentrations in solution and grafting degree of PTFE fiber as well as higher coordination temperature could lead to a significant increase in metal content, especially $\mathrm{Fe}(\mathrm{III})$ and $\mathrm{Cu}$ (II) content of the catalysts. Moreover, $\mathrm{Fe}(\mathrm{III})$ and $\mathrm{Cu}$ (II) ions reacted with the modified PTFE fibers more easily than $\mathrm{Ce}(\mathrm{III})$ ion at the same conditions to form the complexes with higher metal content. $\mathrm{Fe}$ (III) ions fixed on the fiber showed a much powerful catalytic performance for the decomposition of $\mathrm{H}_{2} \mathrm{O}_{2}$ and the oxidative degradation of the dye than $\mathrm{Cu}$ (II) and $\mathrm{Ce}(\mathrm{III})$ ions fixed when three different complexes with similar metal content being employed as the catalysts, respectively. Also, taking into the toxicity of $\mathrm{Cu}$ (II) and $\mathrm{Ce}$ (III) ions and the cheapness of iron salt, thus, Fe(III) modified PTFE fiber complex was proposed to act as an effective catalyst for the dye degradation under visible irradiation. And increasing Fe content could remarkably improve the catalytic activity of the complex. Comparing with the three monometallic complexes, $\mathrm{Cu}-\mathrm{Fe}$ bimetallic modified PTFE fiber complexes exhibited the excellent catalytic activity because of the existence of synergetic effect between $\mathrm{Fe}(\mathrm{III})$ and $\mathrm{Cu}$ (II) ions. Their catalytic activity depended highly on $\mathrm{Cu} / \mathrm{Fe}$ molar ratio. 2.87 is the optimum $\mathrm{Cu} / \mathrm{Fe}$ molar ratio to obtain the best catalytic activity for the bimetallic complexes. However, increasing the amount of $\mathrm{Fe}$ (III) or/and $\mathrm{Cu}$ (II) ions fixed on the fibers resulted in the relatively higher concentrations of both ions leaching from them, especially at low $\mathrm{pH}$ ranges. To sum up, the highest dye degradation efficiency and the accepted concentrations of metal ions leaching from the complexes were found when it was prepared with a mixture 
of $0.05 \mathrm{~mol} \mathrm{~L}^{-1} \mathrm{Fe}$ (III) and $0.05 \mathrm{~mol} \mathrm{~L}^{-1} \mathrm{Cu}$ (II) ions at $50^{\circ} \mathrm{C}$ by poly acrylic acid grafted PTFE fiber as the supported material using a simple exhausting method.

\section{Acknowledgments}

The authors thank the Tianjin Municipal Science and Technology Committee for a Research Program of Application Foundation and Advanced Technology (11JCZDJ24600). This research was also supported in part by a Grant from the Natural Science Foundation of China (20773093).

\section{References}

[1] V. V. Ishtchenko, K. D. Huddersman, and R. F. Vitkovskaya, "Part 1. Production of a modified PAN fibrous catalyst and its optimisation towards the decomposition of hydrogen peroxide," Applied Catalysis A, vol. 242, no. 1, pp. 123-137, 2003.

[2] V. V. Ishtchenko, R. F. Vitkovskaya, and K. D. Huddersman, "Investigation of the mechanical and physico-chemical properties of a modified PAN fibrous catalyst," Applied Catalysis A, vol. 242, no. 2, pp. 221-231, 2003.

[3] R. F. Vitkovskaya, I. G. Rumynskaya, E. P. Romanova, and L. Y. Tereshchenko, "Fibre catalyst from modified polyacrylonitrile fibres," Fibre Chemistry, vol. 35, no. 3, pp. 202-207, 2003.

[4] Z. Han, Y. Dong, and S. Dong, "Copper-iron bimetal modified PAN fiber complexes as novel heterogeneous Fenton catalysts for degradation of organic dye under visible light irradiation," Journal of Hazardous Materials, vol. 189, no. 1-2, pp. 241-248, 2011.

[5] Y. Dong, Z. Han, S. Dong, J. Wu, and Z. Ding, "Enhanced catalytic activity of Fe bimetallic modified PAN fiber complexes prepared with different assisted metal ions for degradation of organic dye," Catalysis Today, vol. 175, no. 1, pp. 299-309, 2011.

[6] Z. Han, Y. Dong, and S. Dong, "Comparative study on the mechanical and thermal properties of two different modified PAN fibers and their Fe complexes," Materials and Design, vol. 31, no. 6, pp. 2784-2789, 2010.

[7] S. Parra, I. Guasaquillo, O. Enea et al., "Abatement of an azo dye on structured C-Nafion/Fe-ion surfaces by photoFenton reactions leading to carboxylate intermediates with a remarkable biodegradability increase of the treated solution," The Journal of Physical Chemistry B, vol. 107, no. 29, pp. 70267035, 2003.

[8] S. Wu, E. T. Kang, K. G. Neoh, H. S. Han, and K. L. Tan, "Surface modification of poly(tetrafluoroethylene) films by graft copolymerization for adhesion improvement with evaporated copper," Macromolecules, vol. 32, no. 1, pp. 186193, 1999.

[9] M. C. Zhang, E. T. Kang, and K. G. Neoh, "Consecutive graft copolymerization of glycidyl methacrylate and aniline on poly(tetrafluoroethylene) films," Langmuir, vol. 16, no. 24, pp. 9666-9672, 2000.

[10] Q. Zhang, S. Zhang, S. Chen, P. Li, T. Qin, and S. Yuan, "Preparation and characterization of a strong basic anion exchanger by radiation-induced grafting of styrene onto poly(tetrafluoroethylene) fiber," Journal of Colloid and Interface Science, vol. 322, no. 2, pp. 421-428, 2008.

[11] C. Xiong and C. Yao, "Preparation and application of acrylic acid grafted polytetrafluoroethylene fiber as a weak acid cation exchanger for adsorption of Er(III)," Journal of Hazardous Materials, vol. 170, no. 2-3, pp. 1125-1132, 2009.

[12] J. F. Wei, Z. P. Wang, J. Zhang, Y. Y. Wu, Z. P. Zhang, and C. H. Xiong, "The preparation and the application of grafted polytetrafluoroethylene fiber as a cation exchanger for adsorption of heavy metals," Reactive and Functional Polymers, vol. 65, no. 1-2, pp. 127-134, 2005.

[13] M. Cheng, W. Song, W. Ma et al., "Catalytic activity of iron species in layered clays for photodegradation of organic dyes under visible irradiation," Applied Catalysis B, vol. 77, no. 3-4, pp. 355-363, 2008.

[14] N. M. El-Sawy and F. Al Sagheer, "Radiation-induced graft polymerization of acrylic acid onto poly(tetrafluoroethyleneperfluorovinyl ether) copolymer films: complexation with some transition metals and biological activity," European Polymer Journal, vol. 37, no. 1, pp. 161-166, 2001.

[15] I. A. Şengil and M. Özacar, "Biosorption of $\mathrm{Cu}$ (II) from aqueous solutions by mimosa tannin gel," Journal of Hazardous Materials, vol. 157, no. 2-3, pp. 277-285, 2008.

[16] C. Xiong, C. Yao, and X. Wu, "Adsorption of rhenium(VII) on 4-amino-1,2,4-triazole resin," Hydrometallurgy, vol. 90, no. 24, pp. 221-226, 2008.

[17] G. Henrici-Olive and S. Olive, Coordination and Catalysis, Chemie, Weinheim, Germany, 1977.

[18] F. L. Y. Lam, A. C. K. Yip, and X. Hu, "Copper/MCM-41 as a highly stable and $\mathrm{pH}$-insensitive heterogeneous photoFenton-like catalytic material for the abatement of organic wastewater," Industrial and Engineering Chemistry Research, vol. 46, no. 10, pp. 3328-3333, 2007.

[19] M. Neamtu, A. Yediler, I. Siminiceanu, and A. Kettrup, "Oxidation of commercial reactive azo dye aqueous solutions by the photo-Fenton and Fenton-like processes," Journal of Photochemistry and Photobiology A, vol. 161, no. 1, pp. 87-93, 2003. 


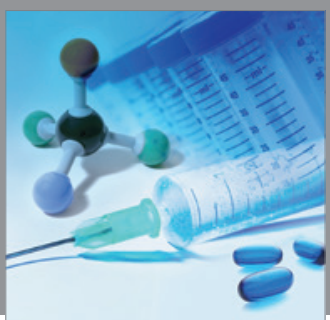

International Journal of

Medicinal Chemistry

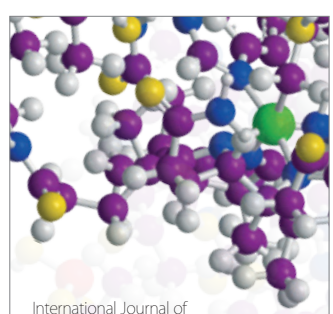

Carbohydrate Chemistry

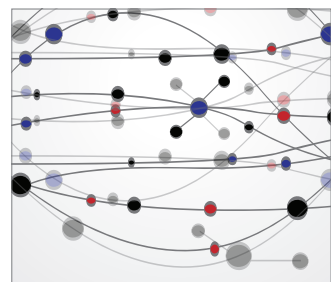

The Scientific World Journal
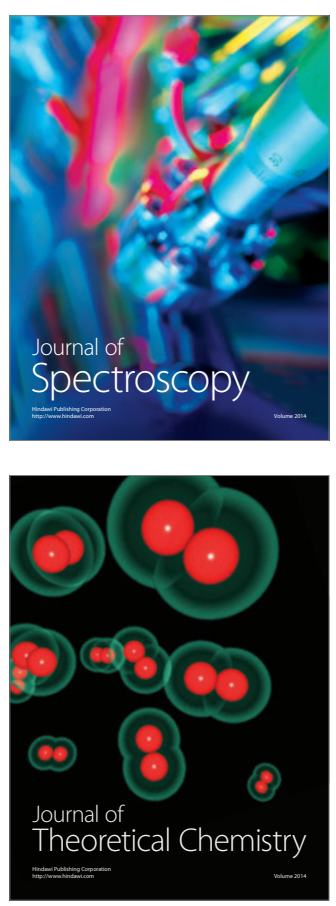
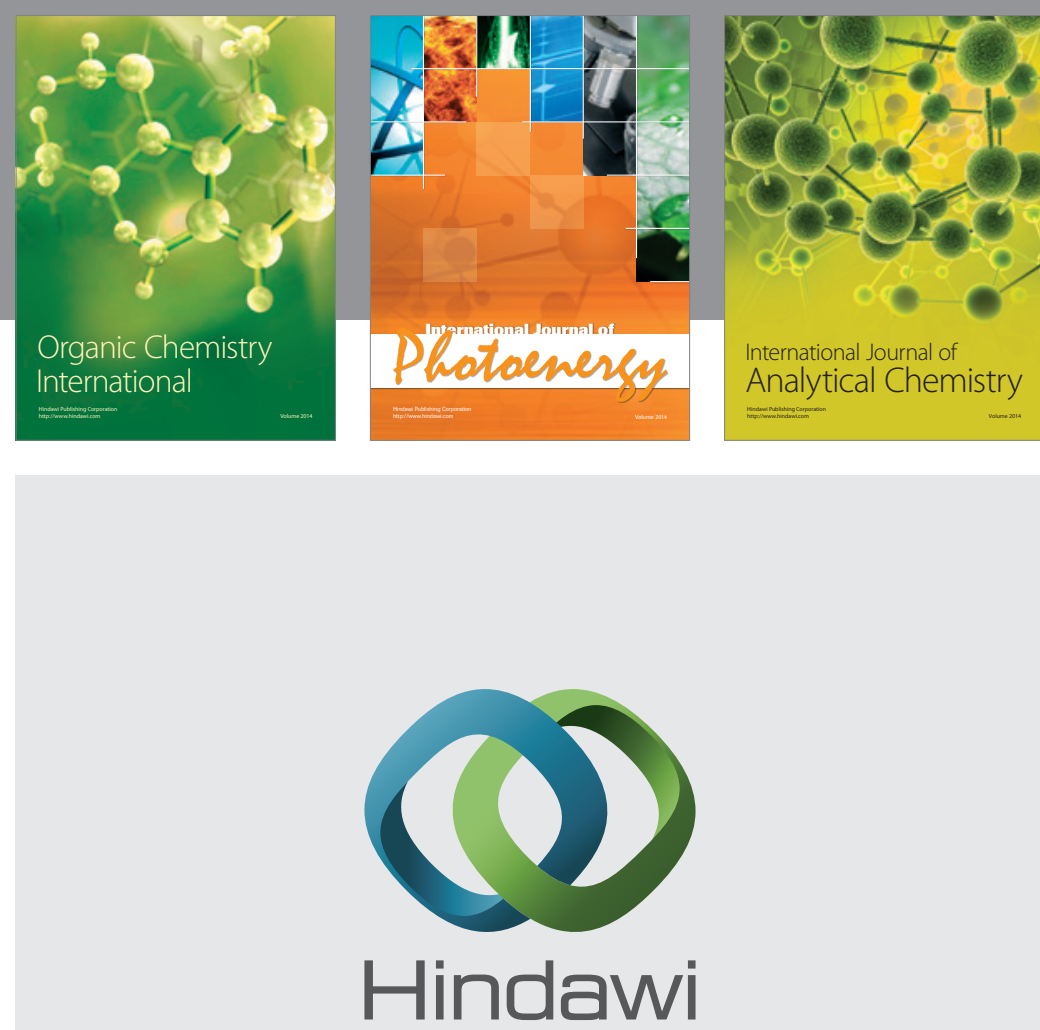

Submit your manuscripts at

http://www.hindawi.com
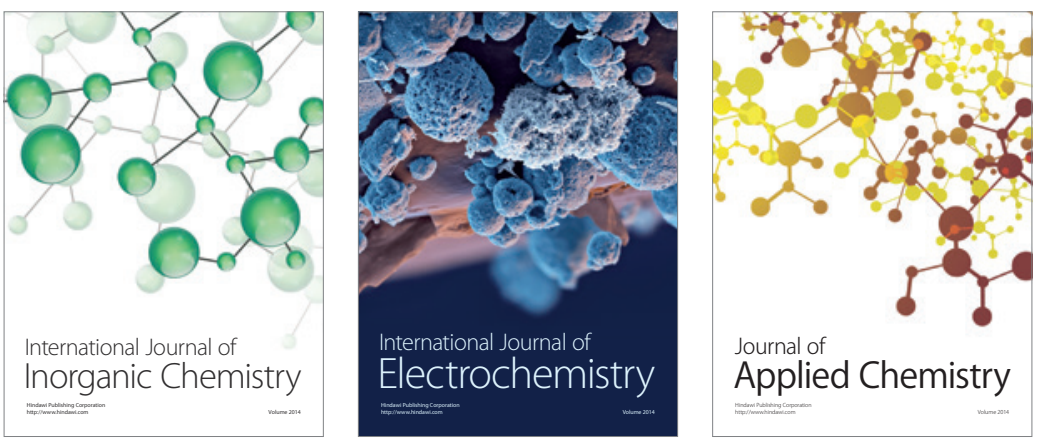

Journal of

Applied Chemistry
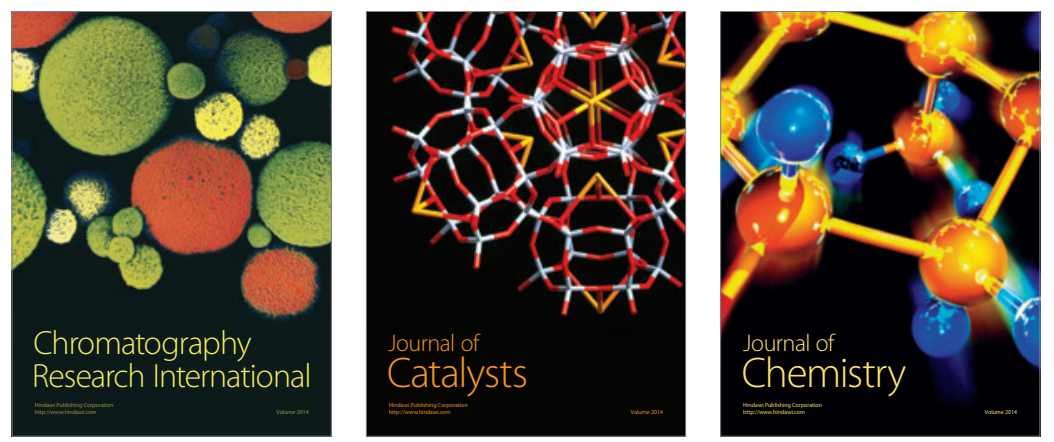
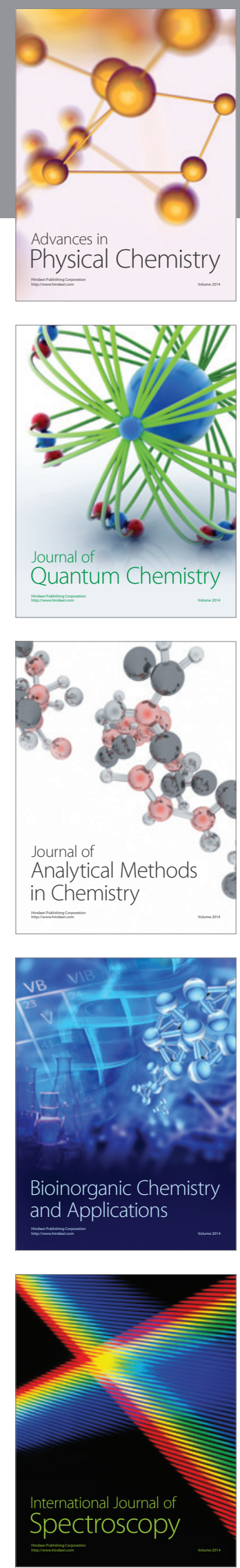